\title{
Testosterone-lowering activity of canola and hydrogenated soybean oil in the stroke-prone spontaneously hypertensive rat
}

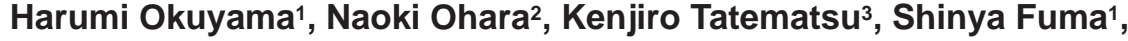 \\ Tomoyuki Nonogaki ${ }^{1}$, Kazuyo Yamada ${ }^{1}$, Yuko Ichikawa ${ }^{1}$, Daisuke Miyazawa ${ }^{1}$, Yuko Yasui ${ }^{1}$ \\ and Seijiro Honma ${ }^{4}$ \\ ${ }^{1}$ Open Research Center for Lipid Nutrition, Kinjo Gakuin University College of Pharmacy, Omori 2-1723, \\ Moriyamaku, Nagoya, Aichi 463-8521, Japan \\ ${ }^{2}$ Hatano Research Institute, Food and Drug Safety Center, Ochiai 729-5, Hadano, Kanagawa 257-8523, Japan \\ ${ }^{3}$ Gifu Pharmaceutical University, Mitahorahigashi 5-6-1, Gifu 502-8585, Japan \\ ${ }^{4}$ Steroid Research Center, ASKA Pharma Medical Co., Shimosakunobe 5-36-1, Takatsuku, Kawasaki, \\ Kanagawa 213-8522, Japan
}

(Received March 31, 2010; Accepted May 11, 2010)

\begin{abstract}
Canola and some other types of oil unusually shorten the survival of stroke-prone spontaneously hypertensive rats (SHRSP), compared with soybean oil, perilla oil and animal fats. Since differential effects of canola and soybean oil on steroid hormone metabolism were suggested by a preliminary DNA microarray analysis as a reason for this, the steroid hormone levels in the serum and tissues of SHRSP fed different oils were investigated. The testosterone levels in the serum and the testes were found to be significantly lower in the canola oil group than in the soybean oil group, while no significant differences were detected in the corticosterone and estradiol levels in tissues. In a second experiment, it was found that hydrogenated soybean oil, with a survival-shortening activity comparable to that of canola oil, also decreased the testosterone level in testes to a similar degree. The testosterone-lowering activity of canola and hydrogenated soybean oil observed in SHRSP was considered in relation to other factors possibly affecting the physiology of SHRSP.
\end{abstract}

Key words: Testosterone-lowering effect, Canola oil, Hydrogenated soybean oil, SHRSP

\section{INTRODUCTION}

The stroke-prone spontaneously hypertensive rat (SHR$\mathrm{SP})$ develops hypertension, and stroke is frequently the cause of death. Using SHRSP, it has been shown that canola oil and several other vegetable oils unusually shorten the survival of SHRSP, compared with perilla oil, flaxseed oil, fish oil and animal fats (Shimokawa et al., 1988; Huang et al., 1996; Ratnayake et al., 2000a). Hydrogenated soybean oil and hydrogenated canola oil shorten the survival of SHRSP similarly (Huang et al., 1997; Miyazaki et al., 1998). Decreased platelet counts (Naito et al., 2000a), increased erythrocyte fragility, severe renal injury involving lesions in blood vessels (Miyazaki et al., 2000) and elevated blood pressure (Naito et al., 2000b) are associated with dietary canola oil. Similar anti-nutritional activities of canola oil have been observed in rats of other strains (Naito et al., 2000b), mice (Kameyama et al., 1996) and pigs (Sauer et al., 1997; Innis and Dyer, 1999). Although the survival-shortening factor in canola oil had been assumed to be phytosterols (Ratnayake et al., 2000b), the factor and the phytosterols have been partially separated by a $\mathrm{CO}_{2}$-supercritical fluid extraction method, indicating that a factor other than triacylglycerol and phytosterols is involved in the survival shortening (Tatematsu et al., 2004a; Ohara et al., 2006). The purpose of this study was to obtain clues for finding the factor. For the purpose, a preliminary DNA microarray analysis was carried out using SHRSP, and the results suggested a disturbance of the steroid hormone metabolism. This article

Correspondence: Naoki Ohara (E-mail: oharan@kinjo-u.ac.jp)

Disclosure of conflicts of interest: The authors have no conflict of interest concerning the work reported in this article. 
H. Okuyama et al.

reports a reduction of testosterone levels in the serum and testes of SHRSP by canola and hydrogenated soybean oil, compared with soybean oil.

\section{MATERIALS AND METHODS}

\section{Animal and diets}

The conventional basal diet (CE-2, Clea Japan, Tokyo, Japan) and test oil were mixed at a 9:1 ratio, and the mixture was pelletized. The diet, containing $12.7 \%$ lipids (27.6 energy \%), was stored under nitrogen gas at $-20^{\circ} \mathrm{C}$ and used within 3 months of preparation. Soybean oil and canola oil were purchased on the local market, and hydrogenated soybean oil for human consumption was obtained from Hamari Chemicals Ltd. (Osaka, Japan). The hydrogenated soybean oil diet contained linoleic acid at 3.8 energy \%. A diet containing soybean oil was used as the control, because CE-2 contains soybean oil as its major fat ingredient. The test diets supplied were replaced every 2 days to keep the peroxide values of the food served below $100 \mathrm{mEq} / \mathrm{kg}$.

SHRSP were obtained from Seack Yoshitomi Co. (Fukuoka, Japan) and maintained in the laboratory. The temperature and humidity in the breeding room were maintained at $23 \pm 3^{\circ} \mathrm{C}$ and $50 \pm 3 \%$, respectively, with a 12-hr day-night light cycle. The rats at 4 weeks of age (6 animals of both sexes and 8 males were assigned to each dietary group in Experiment 1 and Experiment 2, respectively) were given a test diet and deionized water. After feeding with the test diet for 12 weeks, the rats were anesthetized with pentobarbital and sacrificed at 13:00-16:00. The liver and testes were removed, and tissue samples obtained were immediately soaked in RNAlater ${ }^{\circledR}$ solution (Funakoshi, Tokyo, Japan) for microarray analysis or frozen on dry ice and kept at $-80^{\circ} \mathrm{C}$ for determining steroid hormones. The Ethical Committees for Animal Experiments of Nagoya City University and Kinjo Gakuin University approved this study.

\section{Microarray analysis}

A microarray analysis was carried out in Experiment 1. The tissue samples of the liver and testes in RNAlater ${ }^{\circledR}$ solution were dispersed into RNAWIZ (Applied Biosystem Japan, Tokyo, Japan), and the total RNA was extracted according to the manufacturer's instructions. The total RNA was quantified by absorbance at $260 \mathrm{~nm}$. Samples (1 mg, per rat) of the total RNA taken from each of the rats in the same group were combined for the microarray analysis using Rat Oligo Microarray (Agilent Technologies Inc., Santa Clara, CA, USA). Sample processing and assays were carried out by Hokkaido System Science Co. (Sapporo,
Japan).

\section{Determination of tissue hormone levels}

Tissue hormone levels were determined using methods described previously (Shibata et al., 2000). Briefly, ${ }^{2} \mathrm{H}_{3}$-testosterone (CDN ISOTOPES, Quebec, Canada) was added to serum or tissue extracts as an internal standard and placed in a Bond Elut C18 column, and the partially purified steroid hormones were derivatized with 2-fluoro1-methylpyridinium $p$-toluenesulfonate. The resulting derivatives were placed in a Bond Elut C18 column again, and the eluted fractions were injected into a liquid chromatography-mass spectrometry/mass spectrometry (LCMS/MS) apparatus (HP1100, Hewlett-Packard, Palo Alto, CA, USA) and Quattro II (Micromass, Cary, NC, USA) with Atlantis C18 (Waters Japan CO., Ltd., Tokyo, Japan).

For the determination of estradiol, ${ }^{2} \mathrm{H}_{3}$-estradiol (CDN ISOTOPES) was added to serum or tissue extract as an internal standard. The extracted estradiol was first derivatized to estradiol 3-pentafuorobenzylether, and then to a 17-oxy-1-methylpyridin derivative, as described earlier (Shibata et al., 2000). Tissue corticosterone was determined by a radioimmunoassay using ${ }^{3} \mathrm{H}$-corticosterone (Daiichi Pure Chemicals, Tokyo, Japan) and an antiserum.

\section{Statistical analyses}

Data are presented as means \pm S.E.M. Statistical analyses of the two groups were performed using Student's $t$ test. One-way ANOVA, followed by a Tukey-Kramer test, was used for comparing the three groups, using the computer program, KyPlot ver. 2.0 (Kyence Inc., Tokyo, Japan).

\section{RESULTS}

\section{Gross observation}

No deaths occurred in either experiment, while tremors and nasal hemorrhaging were sporadically observed in the canola oil and hydrogenated soybean oil groups. In Experiment 1, there was no difference in body weight gain between the two groups (data not shown). In Experiment 2, body weights at the 12th week were $297 \pm 9 \mathrm{~g}$ (soybean oil group), $269 \pm 12 \mathrm{~g}$ (canola oil group) and $246 \pm 10 \mathrm{~g}$ (hydrogenated soybean oil group), and the difference in body weights of the soybean oil and hydrogenated soybean oil groups was significant $(\mathrm{p}<0.05)$.

\section{Gene expression in the testes}

Gene expression in the liver suggested that steroid hormone metabolism was affected by dietary oils; the genes for cytochrome p450 (CYP) 17 and 3 $\beta$-hydroxysteroid dehydrogenase ( $3 \beta$-HSD) in the canola oil group were 
Testosterone-lowering activity of vegetable oil

down-regulated, compared with the soybean oil group. Gene expressions were also analyzed in the testes, since the liver is not the major tissue synthesizing steroid hormones. As a result, genes for the steroidogenic acute regulatory protein (StAR), which carries cholesterol from the mitochondrial outer membranes to the inner membranes ( $\mathrm{x} 0.3$, as a ratio of the signal in the canola oil group to that in the soybean oil group), and CYP17, which oxidizes the 17 position of the steroid backbone (x 0.5 ), were down-regulated, whereas CYP11B1 (x 1.5), catalyzing the formation of corticosterone and aldosterone, and $17 \beta$ -hydroxysteroid dehydrogenase type 1 (17 $\beta$-HSD, type 1 ), involved in estradiol formation (x 1.5), were up-regulated in the canola oil group. Other types of $17 \beta$-HSD, as well as $3 \beta-\mathrm{HSD}$, were expressed similarly in the two groups. Although the changes in gene expression should have been confirmed by PCR, the steroid hormone levels in the sera and tissues determined directly after obtaining the microarray assay data were remarkable.

Aside from the genes related to steroid hormone metabolism, a large number of genes related to cell replication, differentiation and testis development were differentially expressed in the two dietary groups. Among those differences, 5 genes likely related to vitamin K-related proteins were up-regulated (x 1.6 2.4) in some animals in the canola oil group, as noted earlier [15]. Moreover, the arylhydrocarbon $(\mathrm{Ah})$ receptor and the Ah-related gene were up-regulated (x 1.5) in the canola oil group.

\section{Tissue steroid hormone levels}

The tissue steroid hormone levels obtained in Experiment 1 are shown in Table 1. The corticosterone levels in the serum and the adrenal glands (male and female), and the estradiol levels in the ovaries were comparable between the two groups. The testosterone levels in the prostate glands showed no significant differences, either. However, the testosterone levels in the serum and the testes were significantly lower in the canola oil group than in the soybean oil group.

Experiment 2 included a hydrogenated soybean oil group, because hydrogenated soybean oil exhibited a survival-shortening activity comparable to that of canola oil in SHRSP (Miyazaki et al., 1998). Serum testosterone levels in the canola oil and hydrogenated soybean oil groups tended to be lower than in the soybean oil group. Moreover, testicular testosterone levels in these groups were also significantly lower than in the soybean oil group (Fig. 1). The differences in tissue testosterone levels agreed fairly well between Experiments 1 and 2.

\section{DISCUSSION}

In Experiment 2, the average body weight in the hydrogenated soybean oil group was significantly lower, and that in the canola oil group tended to be lower, than in the soybean oil group. The cause of such a discrepancy is unknown. However, the decreased body weight in the hydrogenated soybean oil group is at least unlikely to be due to linoleic acid deficiency because the basal diet con-

Table 1. Effects of dietary oils on serum and tissue steroid hormone levels

\begin{tabular}{|c|c|c|c|c|}
\hline & & & Canola oil & Soybean oil \\
\hline \multirow[t]{3}{*}{ Serum } & \multirow{2}{*}{$\begin{array}{l}\text { Corticosterone } \\
\text { (ng/ml) }\end{array}$} & Male & $626 \pm 80$ & $598 \pm 42$ \\
\hline & & Female & $939 \pm 131$ & $730 \pm 51$ \\
\hline & $\begin{array}{l}\text { Testosterone } \\
\text { (ng/ml) }\end{array}$ & Male & $1.01 \pm 0.13$ & $2.08 \pm 0.34^{*}$ \\
\hline \multirow[t]{2}{*}{ Adrenal glands } & \multirow{2}{*}{$\begin{array}{l}\text { Corticosterone } \\
\text { (ng/mg tissue) }\end{array}$} & Male & $79.0 \pm 12.9$ & $90.8 \pm 9.6$ \\
\hline & & Female & $106.3 \pm 17.5$ & $101.6 \pm 15.1$ \\
\hline Ovary & $\begin{array}{c}\text { Estradiol } \\
\text { (ng/g tissue) }\end{array}$ & Female & $15.2 \pm 4.4$ & $10.4 \pm 7.0$ \\
\hline Testis & $\begin{array}{l}\text { Testosterone } \\
\text { (ng/g tissue) }\end{array}$ & Male & $68.2 \pm 11.9$ & $101.7 \pm 12.1^{*}$ \\
\hline Prostate gland & $\begin{array}{l}\text { Testosterone } \\
\text { (ng/g tissue) }\end{array}$ & Male & $0.29 \pm 0.04$ & $0.28 \pm 0.03$ \\
\hline
\end{tabular}

Data from Experiment 1. Averages \pm S.E.M. of six rats in each group are represented. Statistical analysis of the differences was performed using Student's t-test. *, $\mathrm{p}<0.05$. 
H. Okuyama et al.

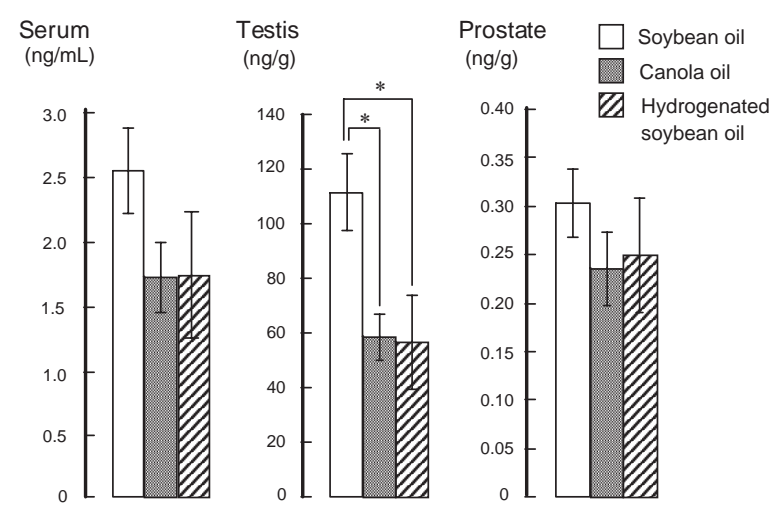

Fig. 1. Effects of dietary oils on tissue testosterone levels. Data from Experiment 2. Averages \pm S.E.M. of eight samples in each group are presented. Statistical analyses were performed using one-way ANOVA, followed by a Tukey-Kramer test.

$*, \mathrm{p}<0.05$.

tained a 3.8-fold greater amount of linoleic acid than its essential amount ( $\sim 1$ energy \%) (Tatematsu et al., 2004b).

In the testes, the expression of genes for StAR and CYP17 was down-regulated. A suppression of StAR activity results in a total reduction of steroid hormone synthesis. On the other hand, decreased CYP17 activity might blunt both, progesterone and dehydroepiandrosterone pathways for testosterone production, which would result in a reduced testosterone production. These data indicated the reduction by canola oil and hydrogenated soybean oil of testicular testosterone level, and this was supported by the plasma and testicular testosterone levels determined, which were decreased in these groups compared with those in the soybean oil group.

The corticosterone levels were not affected, while testosterone levels were decreased. If such a condition were ubiquitous in organs other than the testis, it is possible that dietary hydrogenated soybean oil and canola oil would cause a relative predomination of mineralocorticoid synthesis over sex hormone synthesis. In this context, it should be noted that in Wistar rats fed a canola oil diet, the serum aldosterone level was significantly higher, by $30 \%$, than in those fed a soybean oil diet (Ohara et al., 2008) and that a similar change was also found in SHRSP given canola oil (Naito et al., 2009). Aldosterone plays a crucial role in the cause and exacerbation of vascular injury accompanied with hypertension (Schiffrin, 2006). Canola oil and hydrogenated soybean oil brought about similar, adverse effects in SHRSP: kidney lesions, accelerated bleeding tendency, decreased platelet counts and shortened survival, in addition to the endocrine-dis- turbing activity found here. Thus, some deterioration of hypertension-related cardiovascular injury via an elevated aldosterone level may have relevance to the shortening of life by canola oil and hydrogenated soybean oil in SHRSP.

The unusual effects of canola and hydrogenated soybean oil may not be confined to SHRSP because the decreased platelet counts and unusual survival shortening effects of canola oil have also been observed in pigs (Sauer et al., 1997; Innis and Dyer, 1999). In boars, rapeseed meal caused degeneration and necrosis of the seminiferous epithelium, resulting in the atrophy of the seminiferous tubules, compared with soybean meal (Rotkiewicz et al., 1997). Because whole rapeseed has a greater activity than rapeseed meal in boars, the active principle in rapeseed may be lipophilic and may correlate with the observations reported here.

Early in 1989, Hanis et al. (1989) reported that hydrogenated vegetable oil at 5 weight $\%$ of the diet adversely affected litter size, sperm morphology, regularity of estrous cycle and serum testosterone level in Wistar rats, compared with sunflower oil and low-erucic acid rapeseed oil. Butterfat also decreased serum testosterone level significantly. Some influence of trans-fatty acids in these lipids could be possible, but the hydrogenated vegetable oil and butterfat diets contained marginal amounts of the essential fatty acid, linoleic acid, at 0.54 and 0.38 energy $\%$, respectively. Miller (1990) commented that essential fatty acid deficiency, rather than the effects of trans-fatty acids, might reduce the testosterone levels. However, the existence of some unknown causative cannot be ruled out.

During the partial hydrogenation of vegetable oils, dihydro-vitamin $\mathrm{K}_{1}$, as well as trans-fatty acids, is produced, and it is not converted to vitamin $\mathrm{K}_{2}$. It is postulated that dihydro-vitamin $\mathrm{K}_{1}$ disturbs the vitamin K-dependent reactions involved in the activation of blood coagulation proteins, bone-related proteins and other matrix Gla proteins with diverse calcium-related functions (Okuyama et al., 2007). In fact, 5 genes related to vitamin $K$ reactions were up-regulated in the canola oil group, compared with the soybean oil group. Although dihydro-vitamin $\mathrm{K}_{1}$ has not been identified in canola oil, the presence of minor components with dihydro-vitamin $\mathrm{K}_{1}$-like physiological activities in vegetable oils with survival-shortening activity in SHRSP should be taken into consideration.

Contrary to the risk aspect, one beneficial effect of canola oil has been shown clinically in the Lyon Diet Heart Study (deLorgeril et al., 1994). However, the unusual effects of canola and some other vegetable oils observed in rodents (Huang et al., 1996; Innis and Dyer, 1999; Miyazaki et al., 2000; Tatematsu et al., 2004; Ohara et al., 2009) and piglets (Sauer et al., 1997; Innis and Dyer, 
Testosterone-lowering activity of vegetable oil

1999), as well as those observed in the present experiments, warrant further study to identify the factor and estimate the risks and benefits of these oils in human nutrition.

\section{ACKNOWLEDGMENTS}

This work was supported in part by a Grant for the Promotion of Sciences in Private Universities from the Ministry of Education, Culture, Sports, Science and Technology, a grant from the Ministry of Health, Welfare and Labour, Japan, and the donations to Kinjo Gakuin University from Ohta Oilmill Co., Ltd., Okazaki and Sugiyama Pharmaceutical Co., Nagoya. Part of this study was performed at Nagoya City University, Nagoya.

\section{REFERENCES}

de Lorgeril, M., Renaud, S., Mamelle, N., Salen, P., Martin, J.L., Monjaud, I., Guidollet, J., Touboul, P. and Delaye, J. (1994): Mediterranean alpha-linolenic acid-rich diet in secondary prevention of coronary heart disease. Lancet, 343, 1454-1459.

Hanis, T., Zidek, V., Sachova, J., Klir, P. and Deyl, Z. (1989): Effects of dietary trans-fatty acids on reproductive performance of Wistar rats. Br. J. Nutr., 61, 519-529.

Huang, M.Z., Naito, Y., Watanabe, S., Kobayashi, T., Kanai, H., Nagai, H. and Okuyama, H. (1996): Effect of rapeseed and dietary oils on the mean survival time of stroke-prone spontaneously hypertensive rats. Biol. Pharm. Bull., 19, 554-557.

Huang, M.Z., Watanabe, S., Kobayashi, T., Nagatsu, A., Sakakibara, J. and Okuyama, H. (1997): Unusual effects of some vegetable oils on the survival time of stroke-prone spontaneously hypertensive rats. Lipids, 32, 745-751.

Innis, S.M. and Dyer, R.A. (1999): Dietary canola oil alters hematological indices and blood lipids in neonatal piglets fed formula. J. Nutr., 129, 1261-1268.

Kameyama, T., Ohhara, T., Nakashima, Y., Naito, Y., Huang, M. Z., Watanabe, S., Kobayashi, T., Okuyama, H., Yamada, K. and Nabeshima, T. (1996): Effects of dietary vegetable oils on behavior and drug responses in mice. Biol. Pharm. Bull., 19, 400-404.

Miller, E.L. (1990): Dietary trans fatty acids and reproduction. Br. J. Nutr., 64, 777-779.

Miyazaki, M., Huang, M.-Z., Watanabe, S., Kobayashi, T. and Okuyama, H. (1998): Early mortality effect of partially hydrogenated vegetable oils in stroke-prone spontaneously hypertensive rats (SHRSP). Nutr. Res., 18, 1049-1056.

Miyazaki, M., Takemura, N., Watanabe, S., Hata, N., Misawa, Y. and Okuyama, H. (2000): Dietary docosahexaenoic acid ameliorates, but rapeseed oil and safflower oil accelerate renal injury in stroke-prone spontaneously hypertensive rats as compared with soybean oil, which is associated with expression for renal transforming growth factor-beta, fibronectin and renin. Biochim. Biophys. Acta, 1483, 101-110.

Naito, Y., Yoshida, H., Nagata, T., Tanaka, A., Ono, H. and Ohara, N. (2000a): Dietary intake of rapeseed oil or soybean oil as the only fat nutrient in spontaneously hypertensive rats and Wistar Kyoto rats - blood pressure and pathophysiology. Toxicology, 146, 197-208.

Naito, Y., Kasama, K., Yoshida, H. and Ohara, N. (2000b): Thir- teen-week dietary intake of rapeseed oil or soybean oil as the only dietary fat in Wistar Kyoto rats-change in blood pressure. Food Chem. Toxicol., 38, 811-816.

Naito, Y., Tachibana, S., Okimoto, M., Nagata, T., Furuya, M., Fukumitsu, T. and Ohara, N. (2009): Renal injury in SHRSP fed diet containing canola oil for 6 weeks compared with WKY rats. J. Pharmacol. Sci., 109, Suppl. 1, 178.

Ohara, N., Naito, Y., Nagata, T., Tatematsu, K., Fuma, S., Tachibana, S. and Okuyama, H. (2006): Exploration for unknown substances in rapeseed oil that shorten survival time of stroke-prone spontaneously hypertensive rats. Effects of super critical gas extraction fractions. Food Chem. Toxicol., 44, 952-963.

Ohara, N., Naito, Y., Nagata, T., Tachibana, S., Okimoto, M. and Okuyama, H. (2008): Dietary intake of rapeseed oil as the sole fat nutrient in Wistar rats--lack of increase in plasma lipids and renal lesions. J. Toxicol. Sci., 33, 641-645.

Ohara, N., Naito, Y., Kasama, K., Shindo, T., Yoshida, H., Nagata, T. and Okuyama, H. (2009): Similar changes in clinical and pathological parameters in Wistar Kyoto rats after a 13-week dietary intake of canola oil or a fatty acid composition-based interesterified canola oil mimic. Food Chem. Toxicol., 47, 157-162.

Okuyama, H., Yamada, K., Miyazawa, D., Yasui, Y. and Ohara, N. (2007): Dietary lipids impacts on healthy ageing. Lipids, 42, 821-825.

Ratnayake, W.M., Plouffe, L., Hollywood, R., L’Abbé, M.R., Hidiroglou, N., Sarwar, G. and Mueller, R. (2000a): Influence of sources of dietary oils on the life span of stroke-prone spontaneously hypertensive rats. Lipids, 35, 409-420.

Ratnayake, W.M., L’Abbé, M.R., Mueller, R., Hayward, S., Plouffe, L., Hollywood, R. and Trick, K. (2000b): Vegetable oils high in phytosterols make erythrocytes less deformable and shorten the life span of stroke-prone spontaneously hypertensive rats. J. Nutr., 130, 1166-1178.

Rotkiewicz, T., Bomba, G., Falkowski, J., Glogowski, J., Kozera, W., Kozlowski, M. (1997): Studies on a long-term use of rapeseed products in diets for boars. Pathomorphological changes in the reproductive system, liver and thyroid gland. Reprod. Nutr. Dev., 37, 675-690.

Sauer, F.D., Farnworth, E.R., Bélanger, J.R., Kramer, J.G., Miller, R.B. and Yamashiro, S. (1997): Additional vitamin E required in milk replacer diets that contain canola oil. Nutr. Res., 17, 259-269.

Schiffrin, E.L. (2006): Effects of aldosterone on the vasculature. Hypertension, 47, 312-318.

Shibata, Y., Ito, K., Suzuki, K., Nakano, K., Fukabori, Y., Suzuki, R., Kawabe, Y., Honma, S. and Yamanaka, H. (2000): Changes in the endocrine environment of the human prostate transition zone with aging: simultaneous quantitative analysis of prostatic sex steroids and comparison with human prostatic histological composition. Prostate, 42, 45-55.

Shimokawa, T., Moriuchi, A., Hori, T., Saito, M., Naito, Y., Kabasawa, H., Nagae, Y., Matsubara, M. and Okuyama, H. (1988): Effect of dietary alpha-linolenate/linoleate balance on mean survival time, incidence of stroke and blood pressure of spontaneously hypertensive rats. Life Sci., 43, 2067-2075.

Tatematsu, K., Fuma, S.Y., Nagase, T., Ichikawa, Y., Fujii, Y. and Okuyama, H. (2004a): Factors other than phytosterols in some vegetable oils affect the survival of SHRSP rats. Food Chem. Toxicol., 42, 1443-1451.

Tatematsu, K., Fuma, S.Y., Satoh, J., Ichikawa, Y., Fujii, Y. and Okuyama, H. (2004b): Dietary canola and soybean oil fed to SHRSP rat dams differently affect the growth and survival of their male pups. J. Nutr., 134, 1347-1352. 